Clinical Research Paper

\title{
Impact of age on the survival of pediatric leukemia: an analysis of 15083 children in the SEER database
}

\author{
Yaping Wang ${ }^{1, *}$, Jie Huang ${ }^{1, *}$, Liucheng Rong ${ }^{1, *}$, Peng Wu ${ }^{1}$, Meiyun Kang ${ }^{1}$, Xuejie \\ Zhang ${ }^{1}$, Qin Lu ${ }^{1}$ and Yongjun Fang ${ }^{1}$ \\ ${ }^{1}$ Department of Hematology and Oncology, Children's Hospital of Nanjing Medical University, Nanjing, China \\ * These authors have contributed equally to this work
}

Correspondence to: Yongjun Fang, email: dryjfang@gmail.com

Keywords: surveillance; epidemiology; leukemia; age; Kaplan-Meier

Received: June 29, $2016 \quad$ Accepted: August 26, $2016 \quad$ Published: August 31, 2016

ABSTRACT

BACKGROUND \& AIMS: Age at diagnosis is a key factor for predicting the prognosis of pediatric leukemia especially regarding the survivorship assessment. In this study, we aimed to assess the impact of this prognostic factor such as age in children with pediatric leukemia.

METHODS: In this study, Surveillance, Epidemiology, and End Results Programregistered children with leukemia during 1988-2013 were analyzed. All patients were divided into five groups according to the age at the time of diagnosis $(<1,1-4,5-9$, 10-15, >15 years old). Kaplan-Meier and multivariable Cox regression models were used to evaluate leukemia survival outcomes and risk factors.

RESULTS: There was significant variability in pediatric leukemia survival by age at diagnosis including ALL, AML and CML subtypes. According to the survival curves in each group, survival rate were peaked among children diagnosed at 1-4 years and steadily declined among those diagnosed at older ages in children with ALL. Infants ( $<1$ year) had the lowest survivorship in children with either ALL or AML. However, children (1-4 years) harbored the worst prognosis suffering from CML. A stratified analysis of the effect of age at diagnosis was validated as independent predictors for the prognosis of pediatric leukemia.

CONCLUSIONS: Age at diagnosis remained to be a crucial determinant of the survival variability of pediatric leukemia patients.

\section{INTRODUCTION}

Leukemia is the most common malignant tumor in children worldwide representing up to $30 \%$ of all pediatric cancers [1-3]. For example, approximately 3000 children are diagnosed with leukemia every year in the United States $[4,5]$. Among the major types of leukemia, Acute lymphoid leukemia (ALL) contributes to $76 \%$ of all leukemia cases and $43 \%$ of all deaths of pediatric leukemia patients $[6,7]$. Acute myeloid leukemia (AML) accounts for more than $30 \%$ of the deaths from pediatric leukemia, although it makes up only $15 \sim 20 \%$ of pediatric leukemia $[5,8]$. Chronic myeloid leukemia(CML) constitutes $2 \%$ of all leukemia in children younger than 15 years and $9 \%$ of all leukemia in adolescents between 15 and 19 years, with an annual incidence of 1 and 2.2 cases per million in these age groups, respectively $[9,10]$. With the improvement of diagnosis and treatment criteria, impressive advancements in childhood leukemia treatment entail cure rates reaching $90 \%$ for ALL and $60 \%-70 \%$ for AML [11]. Age is a recognized prognostic factor, with poorer survival for older adults than children, but less attention has been given to the effects of age on prognosis within childhood especially on pediatric leukemia [12-15].

Prognostic factors identified to date include morphology, immunophenotype, molecular and cytogenetic markers as well as host factors such as age at diagnosis and race. For instance, age at diagnosis has been recognized as an important prognostic factor of both incidence and survival of pediatric ALL [16]. Various studies have conducted to pinpoint specific genetic and biological processes occurring in different age groups 
Table 1: Characteristics of patients from SEER database by ages

\begin{tabular}{|c|c|c|c|c|c|c|c|}
\hline \multirow[b]{2}{*}{ Feature } & \multicolumn{7}{|c|}{ Number of patients } \\
\hline & Total & $\underset{<0}{\operatorname{age}(y d)}$ & \begin{tabular}{|l} 
age(yd) \\
$1-4$
\end{tabular} & \begin{tabular}{|l}
$\operatorname{age}(\mathrm{yd})$ \\
$5-9$
\end{tabular} & \begin{tabular}{|l|} 
age(yd) \\
$10-14$
\end{tabular} & $\begin{array}{l}\operatorname{age}(\mathrm{yd}) \\
>15\end{array}$ & $P$ vaule \\
\hline Number & 15083 & 723 & 6074 & 3448 & 2696 & 2142 & \\
\hline Media follow-up(m) & & 32 & 72 & 68 & 66 & 57 & $<0.001$ \\
\hline IQR & & $14-54$ & $54-94$ & $52-88$ & $49-72$ & $22-68$ & \\
\hline Years of diagnosis & & & & & & & 0.187 \\
\hline $1988-2003$ & 4760 & 236 & 1925 & 1135 & 830 & 634 & \\
\hline $2004-2009$ & 6162 & 290 & 2495 & 1345 & 1132 & 900 & \\
\hline $2010-2013$ & 4161 & 197 & 1654 & 968 & 734 & 608 & \\
\hline Sex & & & & & & & $<0.001$ \\
\hline Male & 8407 & 359 & 3311 & 1892 & 1530 & 1315 & \\
\hline Female & 6676 & 364 & 2763 & 1556 & 1166 & 827 & \\
\hline Race & & & & & & & $<0.001$ \\
\hline White & 6373 & 345 & 2309 & 1349 & 1372 & 998 & \\
\hline Black & 2821 & 122 & 1229 & 578 & 498 & 394 & \\
\hline Other & 4912 & 223 & 2201 & 1022 & 794 & 672 & \\
\hline Unkown & 977 & 33 & 335 & 499 & 32 & 78 & \\
\hline Subtype recode & & & & & & & $<0.001$ \\
\hline ALL & 11624 & 340 & 5224 & 2941 & 1858 & 1261 & \\
\hline AML & 2606 & 291 & 666 & 398 & 691 & 560 & \\
\hline $\mathrm{CML}$ & 853 & 92 & 184 & 109 & 147 & 321 & \\
\hline
\end{tabular}

IQR: Interquartile Range; ALL: Acute lymphoid leukemia; AML: Acute myeloid leukemia; CML: Chronic myeloid leukemia

to account for the prognostic value of age at diagnosis. For example, researchers have identified that the lowest survival among patients diagnosed during infancy, followed by children who are diagnosed between 15 and 19 years of age [17]. They also point out that chromosomal rearrangement TEL/AML1, DNA index or BCR/ABL rearrangement may responsible for the poor prognosis at certain age of diagnosis [18-20].

To further clarify the issue of age on pediatric leukemia prognosis, Surveillance, Epidemiology, and End Results (SEER) population-based data during 19882013 were analyzed in this study enrolled ALL, AML and CML [21]. We further employed an independent cohort set including ALL and AML children to analyze the association between the age at diagnosis and prognosis rate.

\section{RESULTS}

\section{Clinicopathologic parameters of patients}

As presented in Table 1, 15083 children were enrolled as diagnosed with leukemia during the 25-year study period (between 1988 and 2013) in the SEER database. Among this, 8407 (55.7\%) were males and 7931 $(44.3 \%)$ were females. Consistent with disease morbidity,
11624 children were suffering from ALL, 2606 children were diagnosed as AML and 853 patients were CML. According to the age classification, 723 were infants, 6074 children were between 1-4 year-old, 3448 children were between 5-9, 2696 children were between 10-14 and 2142 children were elder than 15 . The median follow-up period was 32, 72, 68, 66 and 57 months in each group.

\section{Clinicopathological differences between subgroups}

As illustrated in Table 1, significant differences were found between the 5 groups, including sex (more frequent in men, $P<0.001$ ), race (less frequent in Black; $P<$ 0.001 ), pathologic type (ALL $>$ AML $>$ CML, $P<0.001$ ). However, no difference was found in years of diagnosis $(P=0.187)$.

\section{Impact of age on pediatric leukemia survival outcomes}

The 36-month and 60-month survival rates of pediatric ALL were $19.1 \%$ and $17.2 \%$ in group $1,26.2 \%$ and $24.1 \%$ in group $2,23.2 \%$ and $21.1 \%$ in group $3,21.1 \%$ and $19.1 \%$ in group 4 and $20.2 \%$ and $18.8 \%$ in group 5, respectively. The overall log-rank test showed that the overall 5-year ALL survival was presented in Figure 1A 
Table 2: Univariate survival analysis of patients with leukemia according to various clinicopathological variables.

\begin{tabular}{|c|c|c|c|c|c|c|c|c|c|c|c|c|}
\hline Feature & \begin{tabular}{|l} 
ALL \\
$\mathrm{N}=11624$
\end{tabular} & \begin{tabular}{|l|} 
36-mo \\
ALL(\%)
\end{tabular} & \begin{tabular}{|l}
$60-m o$ \\
ALL(\%)
\end{tabular} & $P$ vaule & \begin{tabular}{|l|} 
AML \\
N=2606
\end{tabular} & \begin{tabular}{|l} 
36-mo \\
AML(\%)
\end{tabular} & \begin{tabular}{|l|} 
60-mo \\
AML(\%)
\end{tabular} & $P$ vaule & $\begin{array}{l}\text { CML } \\
\mathbf{N}=853\end{array}$ & \begin{tabular}{|l|} 
36-mo \\
CML(\%)
\end{tabular} & \begin{tabular}{|l} 
60-mo \\
CML(\%)
\end{tabular} & $P$ vaule \\
\hline Years of diagnosis & & & & $<0.001$ & & & & 0.021 & & & & $<0.001$ \\
\hline $1988-2003$ & 3702 & 17.1 & 9.2 & & 794 & 18.9 & 10.2 & & 264 & 17.9 & 8.2 & \\
\hline 2004-2009 & 4793 & 21.2 & 19.7 & & 1027 & 22.1 & 16.4 & & 342 & 16.9 & 12.7 & \\
\hline $2010-2013$ & 3129 & 28.3 & 25.2 & & 785 & 24.2 & \begin{tabular}{|l|}
19.9 \\
\end{tabular} & & 247 & 37.8 & 30.3 & \\
\hline Sex & & & & $<0.001$ & & & & $<0.001$ & & & & $<0.001$ \\
\hline Male & 6538 & 30.2 & 22.5 & & 1402 & 33.1 & 29.2 & & 467 & 29.8 & 26.2 & \\
\hline Female & 5086 & 31.8 & 23.4 & & 1204 & 28.5 & 21.1 & & 386 & 25.9 & 22.1 & \\
\hline Race & & & & $<0.001$ & & & & $<0.001$ & & & & $<0.001$ \\
\hline White & 4966 & 29.2 & 26.1 & & 1063 & 28.8 & 24.2 & & 344 & 26.1 & 22.5 & \\
\hline Black & 2173 & 23.4 & 19.3 & & 499 & 21.2 & 17.8 & & 149 & 19.7 & 16.3 & \\
\hline Other & 3793 & 26.9 & 23.2 & & 842 & 24.1 & 19.2 & & 277 & 22.9 & 19.8 & \\
\hline Unkown & 692 & 22.1 & 17.1 & & 202 & 22.2 & 18.1 & & 83 & 21.3 & 18.9 & \\
\hline Age & & & & $<0.001$ & & & & $<0.001$ & & & & $<0.001$ \\
\hline $\operatorname{age}(y d)<1$ & 340 & 19.1 & \begin{tabular}{|l|}
17.2 \\
\end{tabular} & & 291 & 18.1 & \begin{tabular}{|l|}
15.1 \\
\end{tabular} & & 92 & 22.3 & 19.7 & \\
\hline age(yd) 1-4 & 5224 & 26.2 & 24.1 & & 666 & 19.3 & 17.2 & & 184 & 17.4 & 14.4 & \\
\hline age(yd) 5-9 & 2941 & 23.2 & 21.1 & & 398 & 26.2 & 23.4 & & 109 & 18.9 & 15.1 & \\
\hline age(yd) 10-14 & 1858 & 21.1 & 19.1 & & 691 & 22.1 & 19.2 & & 147 & 21.5 & 18.8 & \\
\hline $\operatorname{age}(y d)>15$ & 1261 & 20.2 & 18.8 & & 560 & 23.2 & 20.1 & & 321 & 23.2 & 17.9 & \\
\hline
\end{tabular}

mo: month; ALL: Acute lymphoid leukemia; AML: Acute myeloid leukemia; CML: Chronic myeloid leukemia

Table 3: Multivariate Cox model analysis of patients with leukemia according to various clinicopathological variables.

\begin{tabular}{|c|c|c|c|c|c|c|c|c|c|}
\hline Feature & $\begin{array}{l}\text { ALL } \\
\text { HR }\end{array}$ & $\begin{array}{l}\text { ALL } \\
95 \% \text { CI }\end{array}$ & $P^{\mathrm{a}}$ vaule & $\begin{array}{l}\text { AML } \\
\text { HR }\end{array}$ & $\begin{array}{l}\text { AML } \\
95 \% \mathrm{CI}\end{array}$ & $P^{\mathrm{a}}$ vaule & $\begin{array}{l}\text { CML } \\
\text { HR } \\
\end{array}$ & $\begin{array}{l}\text { CML } \\
95 \% \mathrm{CI}\end{array}$ & $P^{a}$ vaule \\
\hline Years of diagnosis & & & $<0.001$ & & & $<0.001$ & & & $<0.001$ \\
\hline $1988-2003$ & 1.0 & Reference & & 1.0 & Reference & & 1.0 & Reference & \\
\hline 2004-2009 & 0.9 & $0.8-1.0$ & & 0.8 & $0.8-0.9$ & & 0.9 & $0.9-1.0$ & \\
\hline 2010-2013 & 0.8 & $0.7-0.9$ & & 0.7 & $0.6-0.8$ & & 0.7 & $0.6-0.8$ & \\
\hline Sex & & & 0.46 & & & 0.22 & & & 0.31 \\
\hline Male & 1.0 & Reference & & 1.0 & Reference & & 1.0 & Reference & \\
\hline Female & 1.0 & $0.9-1.1$ & & 0.9 & $0.7-1.1$ & & 0.9 & $0.8-1.0$ & \\
\hline Race & & & $<0.001$ & & & 0.002 & & & $<0.001$ \\
\hline White & 1.0 & Reference & & 1.0 & Reference & & 1.0 & Reference & \\
\hline Black & 1.6 & $0.7-2.0$ & & 1.4 & $1.1-2.2$ & & 2.1 & $1.1-2.5$ & \\
\hline Other & 1.4 & $0.9-1.6$ & & 1.2 & $1.0-1.5$ & & 1.5 & $1.2-1.9$ & \\
\hline Unkown & 1.5 & $1.3-1.8$ & & 1.3 & $1.0-1.6$ & & 1.8 & $1.6-2.1$ & \\
\hline Age & & & $<0.001$ & & & $<0.001$ & & & $<0.001$ \\
\hline $\operatorname{age}(\mathrm{yd})<1$ & 2.5 & $2.0-3.1$ & & 18.1 & 2.4 & $1.9-2.8$ & 1.1 & $0.8-1.2$ & \\
\hline age(yd) $1-4$ & 0.6 & $0.4-0.9$ & & 19.3 & 1.8 & $1.2-2.3$ & 2.4 & $2.5-2.9$ & \\
\hline age(yd) 5-9 & 1.0 & Reference & & 26.2 & 0.8 & $0.7-0.9$ & 1.9 & $1.6-2.1$ & \\
\hline age(yd) $10-14$ & 1.5 & $1.1-1.8$ & & 22.1 & 1.0 & Reference & 1.0 & Reference & \\
\hline $\operatorname{age}(y d)>15$ & 1.9 & $1.6-2.1$ & & 23.2 & 1.3 & $0.9-1.4$ & 1.2 & $0.9-1.3$ & \\
\hline
\end{tabular}

HR: Hazard ratio; CI: confidence interval; ALL: Acute lymphoid leukemia; AML: Acute myeloid leukemia; CML: Chronic myeloid leukemia

a: $\mathrm{P}$ values were adjusted for years of diagnosis, sex, age, race and age as covariates.

$(P<0.001)$. For AML, the 36-month and 60-month were $18.1 \%$ and $15.1 \%$ in group $1,19.3 \%$ and $17.2 \%$ in group $2,26.2 \%$ and $23.4 \%$ in group $3,22.1 \%$ and $19.2 \%$ in group 4 , and $23.2 \%$ and $20.1 \%$ in group 5 , respectively. The overall log-rank test showed that the overall 5-year AML survival was presented in Figure 1B $(P<0.001)$. The survival rate of CML were different with ALL or AML. The 36-month and 60-month were $22.3 \%$ and $19.7 \%$ in group $1,17.4 \%$ and $14.4 \%$ in group $2,18.9 \%$ and $15.1 \%$ in group $3,21.5 \%$ and $18.8 \%$ in group 4 , and $23.2 \%$ and $17.9 \%$ in group 5, respectively. The overall 5-year CML survival was presented in Figure $1 \mathrm{C}(P<0.001)$. Through the univariate survival analysis, we also found an gender tendency (men), an early year of diagnosis (1988-2003), black race as well as age distribution (infant for ALL and AML, 1-4 year-old for CML) were regarded as significant risk factors for low 60-month pediatric leukemia followup rate (Table 2). 

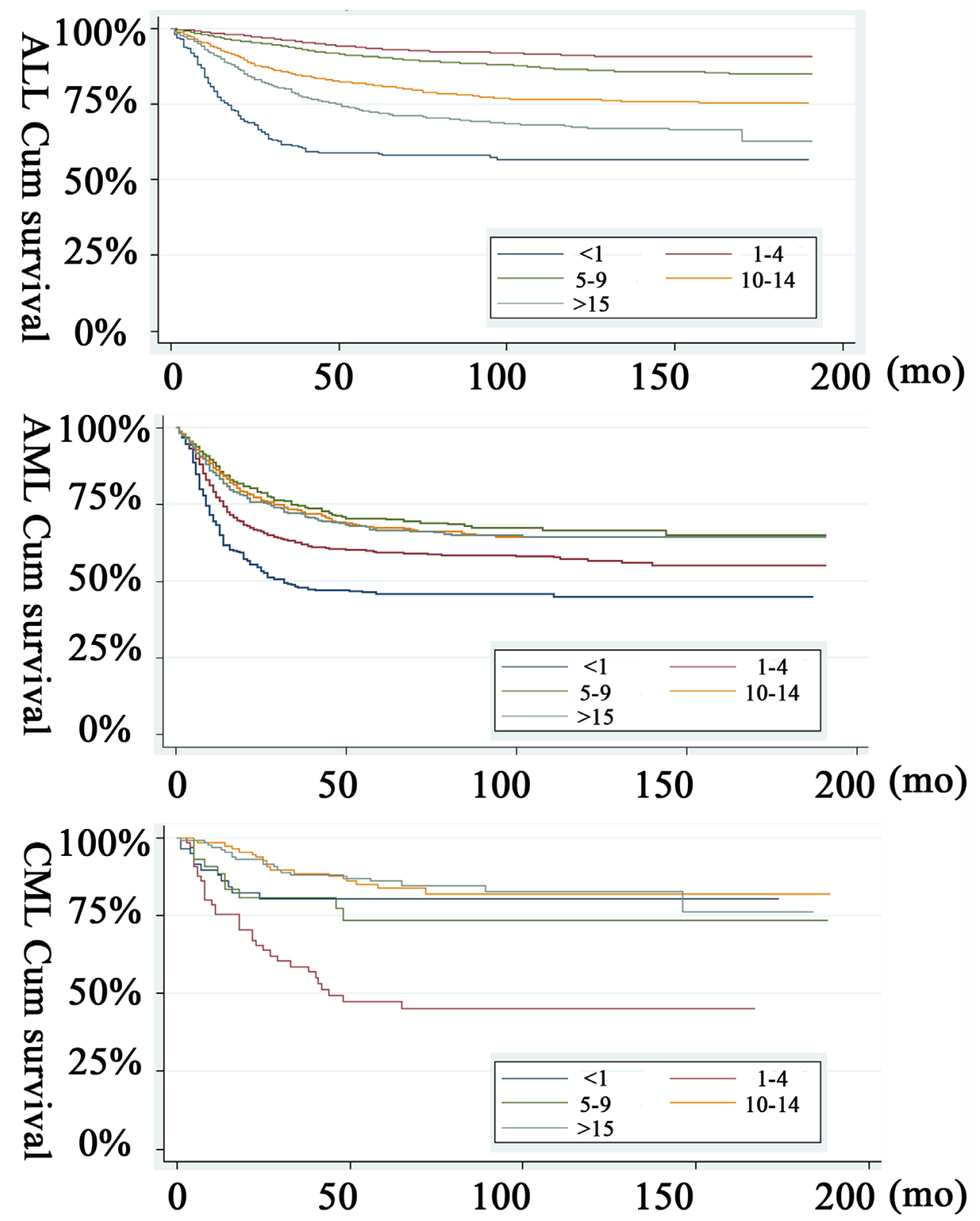

Figure 1: Kaplan-Meier pediatric leukemia survival estimates by age at diagnosis. A. ALL; B. AML; C. CML.

Survival proportions: Survival of ALL

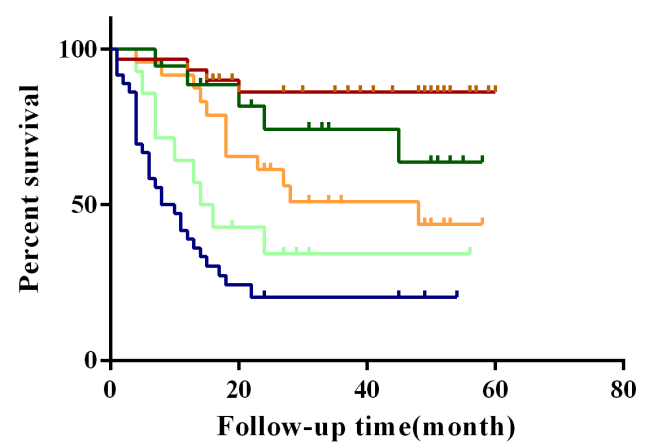

Survival proportions: Survival of AML
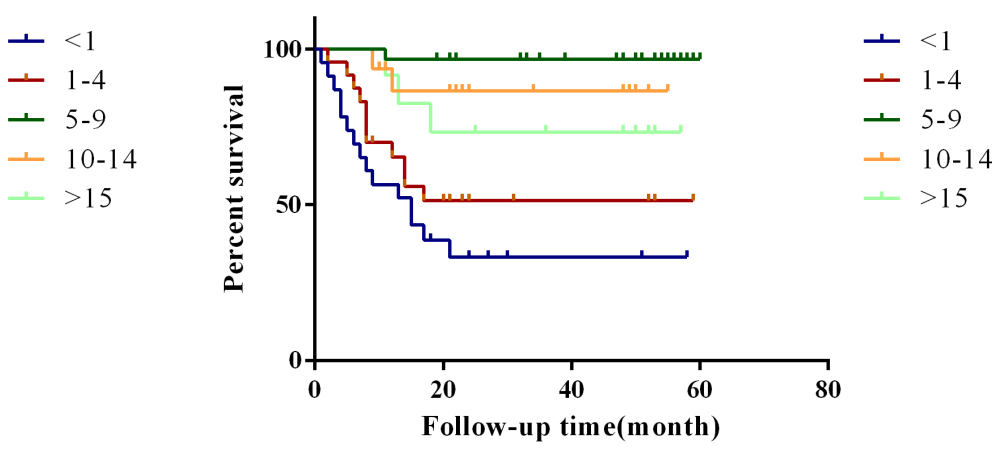

Figure 2: Survival curves of patients with pediatric leukemia in independent cohort set in different age groups. A. ALL; B. AML. 
Multivariate analysis was also performed by the Cox regression model. The following three factors were found to be independent prognostic factors for either ALL, AML or CML (Table 3).

For ALL, the year of diagnosis(2004-2009, hazard ratio (HR) 0.9 , 95\% confidence interval (CI) 0.8-1.0; 2010-2013, HR 0.8, 95\% CI 0.7-0.9), race (Black, HR 1.6, 95\% CI 0.7-2.0; others, HR 1.4, 95\% CI 0.9-1.6; unknown, HR 1.5, 95\% CI 1.3-1.8), age ( $<1$, HR 2.5, 95\% CI 2.0-3.1; 1-4, HR 0.6, 95\% CI 0.4-0.9; 10-14, HR 1.5, 95\% CI 1.1-1.8; > 15, HR 1.9, 95\% CI 1.6-2.1).

For AML, the year of diagnosis(2004-2009, HR 0.8, 95\% CI 0.8-0.9; 2010-2013, HR 0.7, 95\% CI 0.6-0.8), race (Black, HR 1.4, 95\% CI 1.1-2.2; others, HR 1.2, 95\% CI 1.0-1.5; unknown, HR 1.3, 95\% CI 1.0-1.6), age $(<1$, HR $2.4,95 \%$ CI 1.9-2.8; 1-4, HR 1.8, 95\% CI 1.2-2.3; 5-9, HR $0.8,95 \%$ CI $0.7-0.9$; > 15, HR $1.3,95 \%$ CI $0.9-1.4$ ).

For CML, the year of diagnosis(2004-2009, HR 0.9, 95\% CI 0.9-1.0; 2010-2013, HR 0.7, 95\% CI 0.6-0.8), race (Black, HR 2.1, 95\% CI 1.1-2.5; others, HR 1.5, 95\% CI 1.2-1.9; unknown, HR 1.8, 95\% CI 1.6-2.1), age $(<1$, HR $1.1,95 \%$ CI $0.8-1.2 ; 1-4$, HR 2.4, 95\% CI 2.5-2.9; 5-9, HR $1.9,95 \%$ CI 1.6-2.1; > 15, HR 1.2, 95\% CI 0.9-1.3).

Among the three histological type, no statistical difference were observed with regards to sex ( $p=0.46$, $0.22,0.31$, respectively) according to multivariate survival analysis.

\section{Evaluating the SEER database outcomes in an independent cohort set}

To evaluate the reliability of the SEER results, data for 107 eligible ALL pediatric patients and 125 AML from the NCHNMU were analyzed. Patients' demographic characteristics and pathological features were summarized in Supplemental Table 1. Due to the limitation of morbidity, we could only analyze the follow-up data for ALL and AML at this time. The age group was divided as described before. Consistent with the SEER database, it was interesting to note that infant with ALL harbored the worst survival while the children with 1-4 year-old indicated a better prognosis (Figure 2A). In children with AML, we found that either infant or children with 1-4 year old indicated a poor survival rate (Figure 2B).

\section{DISCUSSION}

The prognostic value of age at diagnosis in pediatric leukemia has long been recognized. The present study is conducted to assess the effect of age at diagnosis on the survival patterns of children diagnosed with leukemia including ALL, AML and CML. Our main finding is that there is a significant variation in survival by age at diagnosis, with the worst outcome for children diagnosed in infancy, the best outcome for those diagnosed during the age of 1-4 years in pediatric ALL children. Hossain et al also indicated infants ( $<1$ year) had the lowest survivorship. In a multivariable Cox proportional hazard model stratified by year of diagnosis, those diagnosed in age groups 1-4, 5-9, 10-14, and 15-19 years were $82 \%, 75 \%, 57 \%$, and $32 \%$ less likely to die compared to children diagnosed in infancy, respectively among ALL children [22]. In children with AML, we found that infant and children within 1-4 year-old indicating a worse prognosis. In addition, we also identified that the worst outcome for children diagnosed as CML during the age of 1-4 years. The differential survival patterns of pediatric leukemia by age at diagnosis persist after accounting for the effects of known prognostic factors: sex, race, receipt of radiation therapy, immunophenotype, and the number of primary tumor sites. These patterns may be partly due to a variety of age-dependent favorable and unfavorable clinical and biological features mentioned in the introduction.

Among solid tumor, age was also considered as a predictor for patients' survival. Various studies have also reported that age plays a paradoxical role on the prognosis of HCC [23]. Cho et al. demonstrated that young patients had poorer survival rates than elderly patients due to the a more advanced tumor stage at diagnosis [24]. In this study, the poor prognosis of either ALL or AML in infants might be partial due to a poorer immune system, more advanced stage or chromosome abnormality.

\section{CONCLUSIONS}

There is a differential survival pattern of pediatric leukemia by age at diagnosis. The detailed biological mechanism and environmental processes occurring at different stages of development may give rise to this association. Future research could focus on identifying these processes and elucidating their mechanisms.

\section{PATIENTS AND METHODS}

\section{Patient selection}

The study included 15083 children who were diagnosed with leukemia between ages 0 and 18 years during 1988-2013, whose information was reported to one of the 17 SEER registries. In detail, 11624 children with ALL, 2606 children with AML and 853 children with CML were enrolled. The SEER Cancer Statistics Review (http://seer.cancer.gov/data/citation.html), a report on the most recent cancer incidence, mortality, survival, prevalence, and lifetime risk statistics, is published annually by the Data Analysis and Interpretation Branch of the National Cancer Institute, (Bethesda, MD, USA). The SEER data contain no identifiers and are publicly 
available for studies of cancer-based epidemiology and survival analysis. The National Cancer Institute's SEER*Stat software (Surveillance Research Program, National Cancer Institute SEER*Stat software, www.seer. cancer.gov/seerstat) (Version 8.1.5) was used to identify pediatric patients diagnosed with leukemia based on Site recode International Classification of Diseases for Oncology (ICD-O)-3/WHO 2008. Morphology codes for leukemia were expanded to include the following histologies: 9811, 9814, 9826, 9837, 9846, 9861, 9866, 9867, 9875 and 9920.

This study was based on public data from the SEER database. The data did not include the use of human subjects or personal identifying information. Thus, no informed consent was required for this part of the study. This study was also in compliance with the Declaration of Helsinki of the World Medical Association and was approved by the ethics committee of Nanjing Children's Hospital Affiliated with Nanjing Medical University (NCHNMU).

\section{Age at diagnosis}

The SEER data included a variable of age at diagnosis recorded as $<1,1-4,5-9,10-14$ and $>15$ as reported. This age classification is representative of age based pediatric leukemia risk groupings used in most studies and was adopted for the purpose of this paper.

\section{Year of diagnosis}

The SEER data we obtained was during 1988-2013. We recorded this variable into three groups (1988-2003, 2004-2009, 2010-2013).

\section{Sex}

Sex was a nominal variable in the SEER dataset and used as a binary variable with male as the reference group.

\section{Race}

In the SEER dataset, the variable race contains information of White, Black, Asian/Pacific Islander, and others or unknown. Because of the limited number of subjects, we did not attempt to include the latter two categories in the analysis. We regrouped this variable as White (Caucasian), Black (African American), others (Asian/Pacific Islander, others) and unknowns. White was set as the reference group in our analysis.

\section{Data filter}

Only the behavior code ICD-O-3 recorded as malignant with positive histology diagnosis and the age at diagnosis between 18 and 85 years were included. Patients were excluded if they had incomplete histological type, no evaluation of follow-up, age, sex, race, primary rite were assessed. Adjuvant chemotherapy was not evaluated as the SEER registry does not include this information. The primary endpoint of the study is leukemia, which was calculated from the date of diagnosis to the date of cancer specific death. Deaths were treated as events and deaths from other causes were treated as censored observation.

\section{Statistical analysis}

All the categorical variables were presented as frequency $(\%)$ while the continuous variables were presented as median (interquartile range) or mean(SD). The association between age and clinicopathological parameters was assessed using the chi-square $\mathrm{c}^{2}$ test. Survival curves were generated using the Kaplan-Meier method; differences between the curves were analyzed by using the log-rank test. Multivariable Cox proportional hazards regression models were setup for analysis of risk factors for survival outcomes. All statistical analyses and graph generation were performed using the statistical software package STATA10.0 (Texas, USA). $P<0.05$ was considered significant throughout the study.

\section{Abbreviations}

SEER: Surveillance, Epidemiology, and End Results; ALL: Acute lymphoid leukemia;

AML: Acute myeloid leukemia; CML: Chronic myeloid leukemia; HR: Hazard ratio; CI: confidence interval; IQR: Interquartile Range; mo: month.

\section{ACKNOWLEDGMENTS}

This work was supported by grants from the National Natural Science Foundation (81400116 to Yaping Wang, 81670155 to Yongjun Fang).

\section{CONFLICTS OF INTEREST}

The authors declare that they have no financial conflict of interest

\section{REFERENCES}

1. Lee P, Bhansali R, Izraeli S, Hijiya N and Crispino JD. The biology, pathogenesis and clinical aspects of acute lymphoblastic leukemia in children with down syndrome. 
Leukemia. 2016.

2. Warris LT, van den Heuvel-Eibrink MM, Aarsen FK, Pluijm SM, Bierings MB, van den Bos C, Zwaan CM, Thygesen HH, Tissing WJ, Veening MA, Pieters R and van den Akker EL. Hydrocortisone as an Intervention for Dexamethasone-Induced Adverse Effects in Pediatric Patients With Acute Lymphoblastic Leukemia: Results of a Double-Blind, Randomized Controlled Trial. J Clin Oncol. 2016.

3. Miller TP, Li Y, Kavcic M, Troxel AB, Huang YS, Sung L, Alonzo TA, Gerbing R, Hall M, Daves MH, Horton TM, Pulsipher MA, Pollard JA, Bagatell R, Seif AE, Fisher BT, et al. Accuracy of Adverse Event Ascertainment in Clinical Trials for Pediatric Acute Myeloid Leukemia. J Clin Oncol. 2016; 34:1537-1543.

4. Eidenschink Brodersen L, Alonzo TA, Menssen AJ, Gerbing RB, Pardo L, Voigt AP, Kahwash SB, Hirsch B, Raimondi S, Gamis AS, Meshinchi S and Loken MR. A recurrent immunophenotype at diagnosis independently identifies high-risk pediatric acute myeloid leukemia: a report from Children's Oncology Group. Leukemia. 2016.

5. de Rooij JD, Masetti R, van den Heuvel-Eibrink MM, Cayuela JM, Trka J, Reinhardt D, Rasche M, Sonneveld E, Alonzo TA, Fornerod M, Zimmermann M, Pigazzi M, Pieters R, Meshinchi S, Zwaan CM and Locatelli F. Recurrent genetic abnormalities can be used for risk-group stratification in pediatric AMKL: results of a retrospective intergroup study. Blood. 2016.

6. Freeman DE. Standing surgery of the neck and thorax. The Veterinary clinics of North America Equine practice. 1991; 7:603-626.

7. Schuitema I, Deprez S, Van Hecke W, Daams M, Uyttebroeck A, Sunaert S, Barkhof F, van Dulmen-den Broeder E, van der Pal HJ, van den Bos C, Veerman AJ and de Sonneville LM. Accelerated aging, decreased white matter integrity, and associated neuropsychological dysfunction 25 years after pediatric lymphoid malignancies. J Clin Oncol. 2013; 31:3378-3388.

8. Inaba $\mathrm{H}$, Zhou Y, Abla O, Adachi S, Auvrignon A, Beverloo HB, de Bont E, Chang TT, Creutzig U, Dworzak M, Elitzur S, Fynn A, Forestier E, Hasle H, Liang DC, Lee V, et al. Heterogeneous cytogenetic subgroups and outcomes in childhood acute megakaryoblastic leukemia: a retrospective international study. Blood. 2015; 126:1575-1584.

9. Robinson HM, Martineau M, Harris RL, Barber KE, Jalali GR, Moorman AV, Strefford JC, Broadfield ZJ, Cheung KL and Harrison CJ. Derivative chromosome 9 deletions are a significant feature of childhood Philadelphia chromosome positive acute lymphoblastic leukaemia. Leukemia. 2005; 19:564-571.

10. Chang TY, Dvorak CC and Loh ML. Bedside to bench in juvenile myelomonocytic leukemia: insights into leukemogenesis from a rare pediatric leukemia. Blood. 2014; 124:2487-2497.

11. Xu D, Liu X, Yu WM, Meyerson HJ, Guo C, Gerson SL and Qu CK. Non-lineage/stage-restricted effects of a gainof-function mutation in tyrosine phosphatase Ptpn11 (Shp2) on malignant transformation of hematopoietic cells. J Exp Med. 2011; 208:1977-1988.

12. Webb DK, Harrison G, Stevens RF, Gibson BG, Hann IM, Wheatley K and Party MRCCLW. Relationships between age at diagnosis, clinical features, and outcome of therapy in children treated in the Medical Research Council AML 10 and 12 trials for acute myeloid leukemia. Blood. 2001; 98:1714-1720.

13. Razzouk BI, Estey E, Pounds S, Lensing S, Pierce S, Brandt M, Rubnitz JE, Ribeiro RC, Rytting M, Pui CH, Kantarjian $\mathrm{H}$ and Jeha $\mathrm{S}$. Impact of age on outcome of pediatric acute myeloid leukemia: a report from 2 institutions. Cancer. 2006; 106:2495-2502.

14. Creutzig U, Buchner T, Sauerland MC, Zimmermann M, Reinhardt D, Dohner H and Schlenk RF. Significance of age in acute myeloid leukemia patients younger than 30 years: a common analysis of the pediatric trials AML-BFM 93/98 and the adult trials AMLCG 92/99 and AMLSG HD93/98A. Cancer. 2008; 112:562-571.

15. Lange BJ, Smith FO, Feusner J, Barnard DR, Dinndorf P, Feig S, Heerema NA, Arndt C, Arceci RJ, Seibel N, Weiman M, Dusenbery K, Shannon K, Luna-Fineman S, Gerbing RB and Alonzo TA. Outcomes in CCG-2961, a children's oncology group phase 3 trial for untreated pediatric acute myeloid leukemia: a report from the children's oncology group. Blood. 2008; 111:1044-1053.

16. Smith M, Arthur D, Camitta B, Carroll AJ, Crist W, Gaynon P, Gelber R, Heerema N, Korn EL, Link M, Murphy S, Pui CH, Pullen J, Reamon G, Sallan SE, Sather H, et al. Uniform approach to risk classification and treatment assignment for children with acute lymphoblastic leukemia. J Clin Oncol. 1996; 14:18-24.

17. Holmqvist AS, Wiebe T, Hjorth L, Lindgren A, Ora I and Moell C. Young age at diagnosis is a risk factor for negative late socio-economic effects after acute lymphoblastic leukemia in childhood. Pediatr Blood Cancer. 2010; 55:698707.

18. Dordelmann M, Reiter A, Borkhardt A, Ludwig WD, Gotz N, Viehmann S, Gadner H, Riehm H and Schrappe M. Prednisone response is the strongest predictor of treatment outcome in infant acute lymphoblastic leukemia. Blood. 1999; 94:1209-1217.

19. Lauten M, Stanulla M, Zimmermann M, Welte K, Riehm $\mathrm{H}$ and Schrappe M. Clinical outcome of patients with childhood acute lymphoblastic leukaemia and an initial leukaemic blood blast count of less than 1000 per microliter. Klin Padiatr. 2001; 213:169-174.

20. Roberts KG, Li Y, Payne-Turner D, Harvey RC, Yang YL, Pei D, McCastlain K, Ding L, Lu C, Song G, Ma J, Becksfort J, Rusch M, Chen SC, Easton J, Cheng J, et al. Targetable kinase-activating lesions in Ph-like acute lymphoblastic leukemia. N Engl J Med. 2014; 371:10051015. 
21. Adams SV, Newcomb PA and Shustov AR. Racial Patterns of Peripheral T-Cell Lymphoma Incidence and Survival in the United States. J Clin Oncol. 2016; 34:963-971.

22. Hossain MJ, Xie L and McCahan SM. Characterization of pediatric acute lymphoblastic leukemia survival patterns by age at diagnosis. Journal of cancer epidemiology. 2014; 2014:865979.

23. Chen $\mathrm{CH}$, Chang TT, Cheng KS, Su WW, Yang SS, Lin $\mathrm{HH}$, Wu SS, Lee CM, Changchien CS, Chen CJ, Sheu JC, Chen DS and Lu SN. Do young hepatocellular carcinoma patients have worse prognosis? The paradox of age as a prognostic factor in the survival of hepatocellular carcinoma patients. Liver Int. 2006; 26:766-773.

24. Cho SJ, Yoon JH, Hwang SS and Lee HS. Do young hepatocellular carcinoma patients with relatively good liver function have poorer outcomes than elderly patients? J Gastroenterol Hepatol. 2007; 22:1226-1231. 